\title{
Physical Planning Policies on Lagos Island and Their Effects on Urban Morphology
}

\author{
Folahan Anthony Adenaike ${ }^{1}$, Akunnaya Pearl Opoko², Roseline Abidemi Kosoko ${ }^{3}$ \\ ${ }^{1}$ Department of Architectural Technology, Lagos State Polytechnic, Ikorodu, Nigeria \\ ${ }^{2}$ Department of Architecture, College of Science and Technology, Covenant University, Otta, Nigeria \\ ${ }^{3}$ Department of Urban and Regional Planning, Lagos State Polytechnic, Ikorodu, Nigeria
}

Email address:

folahanadenaike@gmail.com (F. A. Adenaike), pearlopoko@yahoo.com (A. P. Opoko), kosokoroseline@yahoo.com (R. A. Kosoko)

\section{To cite this article:}

Folahan Anthony Adenaike, Akunnaya Pearl Opoko, Roseline Abidemi Kosoko. Physical Planning Policies on Lagos Island and Their Effects on Urban Morphology. Urban and Regional Planning. Vol. 5, No. 2, 2020, pp. 50-60. doi: 10.11648/j.urp.20200502.13

Received: March 5, 2020; Accepted: June 10, 2020; Published: June 28, 2020

\begin{abstract}
Physical planning is perhaps the strongest tool in the development of the urban form. It is the visible limb of the state that is used to direct and control development. In Lagos State, physical planning is used more in "development control" rather than "development planning". It also comes into use in the many instances of urban renewal. The rapid urbanization witnessed by Lagos State brought about a sprawl on the whole of Lagos Island. The combination of rapid urbanization, physical planning policies and the cultural heritage of the area have evolved a cocktail of highly diverse styles in the buildings and metropolitan form within the same continuum. This research examines the physical planning policies on Lagos Island over a twenty-year period (1995-2015) and their direct effects on the evolution of the city while trying to control development. The research is qualitative and assessment is based on literature, government records, field interviews, digital photographs and satellite images of the city. The study concluded that the physical planning policies were contingent, responding to issues within successive prompts in time. No holistic policies were put in place to address far reaching issues like a sustainable urban design model to be pursued over time. There is no blueprint for the development of the city. The policies only addressed "growth and development" without prescribed limits. It a classic case of organic development with ineffective controls. The end result is chaotic and needs to be addressed.
\end{abstract}

Keywords: Architecture, Congestion, Development Control, Market City, Public Spaces, Urban Form, Urban Renewal

\section{Introduction}

From independence in 1960, Lagos Island was the seat of both the federal and state governments. This condition persisted for over twenty years. Before the relocations of the federal and state capitals, the ministries and parastatals occupied the southern fringe of the city while the center retained its sedentary outlook with a polycentric matrix of a large market city. The Yoruba cities of Southwest Nigeria usually evolve around the traditional ruler's palace with a market next to it [1]. On Lagos Island, the state and federal governments developed outlying areas and executed "eminent domain" from the western fringe where the two major bridges connecting the mainland are located through the Southern fringes along the lagoon to the eastern fringe towards Victoria Island and Ikoyi. This move, avoided the traditional holds in the city cores with the slum and market proliferation that was developing there. The architecture of these areas is remarkably different from that of the city center. The oil boom of the 1970s brought about increased commercial activities and the markets on the island began to fuse from then. Before this period, there were three major markets. Idumota market, Isale-Eko and Jankara. The major roads linking these major markets and the smaller routes became fully commercialized, changing the outlook of the city. The architecture of the city evolved faster too. The traditional compounds were mud houses around central courts and they spanned the whole island at first. By the late 1970s, the mud houses became modernized with sand and cement rendering to give a smoother look. The storey buildings were mainly of vernacular and Brazilian architectures. They had hipped frontal roofs and concrete balustrades lining wide vestibules at the ground floor and 
balconies at the first floor with ornamented window hoods around wooden windows. They were gradually renovated or replaced to have shops on the ground floor and congested tenement rooms on the first floor. While the residential appeal of the area diminished, the commercial attraction continued to soar. It was more economically viable to locate a business on Lagos Island than any other place in the Lagos metropolis. The factories were however edged out due to traffic congestion and lack of space.

The race for economic benefits by the indigenous family holds, speculators, local and state governments sent the whole city into an uncontrolled urbanization sprawl from the 1980s. Areas close to the ministries were acquired and developed to erect high-rise office buildings by the private sector while the rest of the island was left to develop organically. [2] and [3] had identified this kind of urbanization as self-defeating. Their school of thought had argued that unbalanced allocation of socio-economic resources which may fuel political interest will eventually throw the urban space into dysfunctionalism. The inherent value of the indigenous architecture of the island was never considered in the urbanization processes.

The physical planning policies made no attempt at preservation. Rather, efforts were inclined towards integrating the space standards in the traditional homesteads into the acceptable government standards by shifting the standards in the areas of setbacks, space use and space allocation [4]. The policies are usually enacted by the state government with contributions from the ministries of environment, physical planning and works. Once passed into law, the onus of enforcement and implementation rests on the local government and the divisional planning authority. The ministry of physical planning plays a supervisory role in the enforcement process. The government only participates directly in infrastructural development and erection of public buildings. This level of participation accounts for very little in the totality of the city structure. The buildings which constituted the bulk of the form of the city are privately owned. As a developing economy, the quest for more capital is always very overwhelming for the state authorities [5]. The state government uses all its arms to drive revenue including the physical planning ministry. The rates and amounts charged for services of the ministry are always being reviewed to increase revenue. There is also a conscious effort to encourage property owners who are yet to fully regularize and document their ownership to do so. Some physical planning policies are tailored to the peculiarity of the context. The fragmentation of properties due to the traditional tenure and inheritance system gave rise to very small parcels of land that are difficult to accommodate in the regular space standards for building approval. The government reduced the state standards for setbacks and parking space allotment on the island to accommodate existing and proposed structures that would have fallen foul of the standards. The property owners were thus encouraged to formally regularize their holds. This meant more economic benefits for the government at a great cost for the functionality of the urban environment. The public open spaces which were used for cultural events were taken over and developed into shopping centers and offices. The physical planning policies also allowed the taking over of the traditional markets for development into modern structures by developers for higher financial returns to those concerned. Despite these accommodations by the physical planning policies, the outlook of the city never appeared prosperous. Lagos is described as a city of economic stagnation and dysfunctionalism $([6,7])$.

By the early 1990s all the public open spaces on Lagos Island except Campus Square had been lost. A situation occasioned by lack of preservative intent of the physical planning policies. Physical planning policies should be given time to mature in the urban space before assessment. Where speculators and economic gains by uninformed arms of government are involved, quick returns often overtake deeper reasoning [8]. For an entity as large and complex as a city, only the long-term results determine the success of any urban planning program [9]. This research is considering physical planning policies that were enacted from 1995 to 2015. Before 1995, the public open spaces had been built up. The landscaped areas which were very few had also vanished. There was very little left of the traditional compounds which had become slums and squatter settlements for traders and the indigenous population. Very few of the monumental structures of indigenous architecture like the outstanding traditional houses were preserved. Most of the buildings were pulled down in the late 1980s to build shops and offices. The street layout remained without a conscious street design by the physical planning policies. The building clusters were heavy along the major streets overlooking market activities at street level while the traditional holds had fused into an undiscernible form.

Development though desirable must be managed [10]. Without proper management, urban development easily loses focus and schemes eventually spill over their manageable limits due to the complexity of the urban environment. There is an emerging school of thought that over-commercialized cities will eventually witness a dip in property values and attraction [11].

\section{Methodology}

The study is a qualitative research that sought to explain the present metropolitan space and form with respect to the physical planning policies of the period between 1995 and 2015. The paper is based on views of previous publications, current images of the city layout, interviews and field observation. The physical planning policies which consist of changes in previous policy positions, schemes of urban renewal and upgrade of transportation system since 1995 were analyzed with respect to their effects on the architecture of the area. Satellite images of the current layout of the city were captured for analyzing the current urban form and city layout. A table of the policies and their effects on the urban form was generated for easy reference. The cityscape in close 
views were taken with digital camera to capture the building clusters for architectural interpretation.

Available literature researched dwelt on the historical antecedents of the physical planning machinery and implementation problems facing the policies of the present in the whole of Lagos State. Publications that have reported the effects of physical planning in Lagos State were not readily available. For Lagos Island, only newspaper articles were found in this respect. The articles only made mention of the political implications of the compositions of the government bodies that handled physical planning in the city. Some others mentioned the physical planning measures being put into law and issues of compliance. Articles on the architecture and urban morphology are not prominent. Searches were conducted for published articles in Google Scholar and the internet with "Lagos Island Planning" as search words. More relevant information were acquired with the wider search approach. This assisted in putting up a brief history of the physical planning procedures on Lagos Island from the mid-1800s to the present time. A history of the growth and development of the island was also put together from the search. Photographic records on the different stages of development of Lagos Island were obtained from the Internet. Interviews were conducted with operatives of the government ministries involved in physical planning. The interviews provided the bulk of the data that were analyzed in the findings of the research. Having itemized the relevant policies in the research time frame and other information, the research proceeded to the field to confirm and assess the information collected. Satellite images and photographs of the present situation were analyzed for correlation with the policies that have been enacted in recent times. Conclusions were drawn and positions were taken from the information evolving out the exercise.

Cities will continue to evolve on their own with or without interference or external influences. The urban form of the city is affected by all manners of socio-cultural, economic and political inputs. Care must be taken to only identify those aspects of the morphology that have been modified by the direct execution of physical planning policies in the period under scrutiny. Analysis in urban morphology and design is a very subjective field of endeavor [12]. Every analysis must be subjected to explanation once a strong position is taken. Obvious elements in describing forms in architecture may be acceptable where there is a graphical representation of the element. This paper presentation to a large extent is devoid of any subjective positions. The facts are presented as cited from records, other writers and as recorded from activities on ground. The conclusions are empirically deducted from presented facts and all positions are supported with documented physical evidence and photographs.

\section{An Overview of Physical Planning in Lagos Area}

Efforts towards physical planning in Lagos can be traced to the late nineteenth century. The legislations at this period were to curb the menace of poor sanitation and provide recreation for the colonialists. In 1873, an edict was promulgated instructing residents to maintain a weekly cleaning exercise [13]. A sanitary board was also established at the turn of the century to supervise and advice on policies that can foster a cleaner and more hygienic environment [14]. The discovery in 1927 that mosquitoes were the vector for the transmission of malaria instigated the first real effort at urban physical planning. Ordinances were put in place to maintain this physical separations in 1914, 1915, 1917 and 1921 [15]. These laws did not prevent the influenza epidemic in the mid-1920s which also affected the Europeans. The neglect of the highly populated and dense native settlements particularly on Lagos Island gave birth to the Lagos Executive Development Board (LEDB) in 1925 [16]. This board was involved in land use planning, building plan approval and provision of mass housing till 1972 when it was replaced by the Lagos State Development and Planning Corporation (LSDPC). Physical planning resided with the Ministry of Environment and Physical Planning. The congestion and commercial viability of the island made the ministry to shift grounds on so many issues. Car parking requirements, setbacks of buildings from the road and adjoining properties and land use requirements were adjusted to accommodate the contraventions that were present. Defaulters were made to pay fines known as "contravention penalties" to the state government. Enforcement would have required the property owners to demolish parts of their erected structures. By 1991, physical planning in Lagos area took a new turn. The state government decided to invest more directly and indirectly in the development of the commercially viable areas.

Because of the centrality of Lagos Island and the consequent intrusion into the polity of the area by all arms of government, more administrative bodies were vested on it to manage physical development. While the Ministry of Environment and Physical Planning managed the physical planning policies and implementation, the state government believed that more bodies should be in place to fast-track development. The state government ceded the domain of development control to the ministry to administer. Development planning execution for growth was assigned to Lagos State Urban Renewal Authority (LASURA) on the island and Lagos Mainland. Another body, New Towns Development Authority is more active on the Lekki peninsula which is a fast growing area to the north of the island. LASURA was first established in 1991 as Lagos State Urban Renewal Board (LASURB) with the following objectives. To enhance development and improve the living conditions of communities in Lagos, to move into blighted areas and improve their infrastructure, to support a sustainable environment and create empowerment in communities and to procure affordable and decent housing in poorer communities. From its terms of reference, the body was supposed to cover the whole of older Lagos in its operations. It is however pertinent to note that most of its 
activities in urban renewal were limited to Lagos Island. Urban renewal in this light must include a holistic approach to upgrade the urban setting by enhancing a cluster of urban systems. The body plunged itself into the development control process as certain levels of building plan approval bureaucracy were routed through the board for vetting. The impact of its activities is felt more on the island as it sought to change the outlook of the city. It supervised the gentrification and property acquisition by private investors who acquired land in the center of the city as property developers [17]. Family compounds were leased on agreement to the investors to build larger and more economically viable structures. Road rehabilitation and drains were also constructed as part of infrastructural development. In 1996 another body to manage the environment was established. It is the Lagos State Environmental Protection Agency (LASEPA). Its functions were to monitor and control sources of environmental pollution and make suggestions for their management to the state government. Over the years, the activities of this body have been streamlined towards waste management and the impact on physical planning policies is not being felt. Subsequently, so many parastatals have evolved in Lagos state whose names appear to link them to urban physical planning but with minimal input into the physical planning policies of the state. Lagos State Infrastructural Maintenance and Regulatory Agency (LASIMRA) and Urban Furniture Regulatory Agency (UFRU) only deal with fixed communications equipment. The Ministry of Environment and Physical Planning was split into two bodies in 2003, namely the Ministry of the Environment and the Ministry of Physical Planning. From then, the Ministry of Physical Planning through the district town planning offices and downstream parastatals like LASURA has been responsible for physical planning policies and implementation in Lagos State. The body has since been renamed the "Ministry of Physical Planning and Urban Development”.

\section{Sustainability of Physical Planning Policies}

With the emergence of the sustainability concept, there has been a complete paradigm shift from "growth and development"; in urban studies to" sustainable development". When urban studies which is a very wide study area is limited to studies in physical planning and development, it is usually restricted to infrastructure and metropolitan form. Urban sustainability is a balance within three ends. Ecology, social development and economic growth. For physical planning and development to be sustainable, it must support and nurture these three ideals. All the concepts for sustainable cities that have been developed over the years are only possible in upgrading or renewing old cities towards the new concept or building entirely new cities. Ebenezer Howard's concept of the Garden City is the progenitor of the urban sustainability movements [18]. These sustainable cities concepts culminated in the concepts of Ecocity in the 2000s [19]. [20] were able to reduce all the concepts into two major brands that are relevant in today's world. The Smart-city and the Sustainable-city. For over a century, the eco-friendliness of the built up environment has remained relevant in city planning. The concept of the Sustainable city was among the first properly articulated position for directing the vision of urban development after the submissions of the Bruntland Commission (World Commission on Environment and Development, 1987) on environmental sustainability [21]. The smart-city is an upgrading of the basic sustainability concepts to include information and communication technology [22].

With so many different concepts emerging to guide the development of urban centers towards the realm of sustainable existence, the need arose, to assess the task performance of the compliance to the concepts. The predominant tools for assessing urban sustainability like Leadership in Energy and Environmental Design for Neighborhood Development (LEED-ND), British Research Establishment Assessment Method for communities (BREEEAM Communities), Comprehensive Assessment System for Built Environment Efficiency for Urban Development (CASBEE-UD) and Global Sustainability Assessment System (GSAS) are only able to give relevant assessment in built up cities. Their assessment indices can only be applied after implementation and a possible time lag to allow for attrition. They cover energy, renewable materials and sustainable sites in general $([23,24])$. The design of tools to measure the sustainability of physical planning laws and principles are yet to be extensively researched into. The level of compliance to physical planning policies can easily be determined but the policies always have aims that are conceptual and not absolute. They will only manifest in physical forms over a period that may extend considerably. Their manifestations are also continuous in a general direction unless another policy position halts their progression. Physical planning policies are positions that guide development towards goals that are desirable in the urban setting. Their implementation may be absolute to achieve general trends in the urban development. If a municipal authority legislates that all buildings must maintain a certain setback space in their frontages, the goal may be to reduce street parking of cars in the immediate and improve traffic flow in the long run. If the city develops vertically within a short period and more housing units are contained within the buildings, parking within the legislated setbacks may become inadequate. Residents ultimately have to extend to the roads for parking and the existing setback standards may need to be reviewed. Another approach may be to give limits for street parking. The earlier planning policy is thus rendered ineffective with respect to the ultimate goal of achieving improved flow of traffic.

For a physical planning policy to be sustainable, it must be "sustained" until it has fully achieved its set out objectives. The criteria for assessing how sustainable a physical planning policy is, differ from the criteria for assessing how 
sustainable an urban environment is. A sustainable city is evaluated on how well the urban systems can balance the ecological environment with the economic environment and the social welfare of the inhabitants. The sustainable physical planning policy is evaluated on how long it remains valid against targeted objectives without a recourse to previous positions or new policies. If a policy position will not last or achieve the set objectives which must include that of a sustainable environment, then the policy is not sustainable. Most of the physical planning measures in Lagos are spontaneous and incremental [6]. Long term critical and comprehensive approach to planning is not evident in the evolution of metropolitan areas in the third world [25].

\section{Physical Planning and Urban Morphology}

Physical planning may guide decisions in site selection, building orientation, land use and volumetric development limits for buildings and urban spaces. This should be in line with the urban design concept for the design of the city. Where the city has an existing form that has developed on socio-cultural precepts, the planning laws should guide urban upgrade programs and further development. The desired form of the city should be guided by the physical planning laws and other policy positions that can impact directly and indirectly on how the city is developing. [26] proposed the use of ecological wisdom and co-optation of experts from different fields like sociology, ecology and economics when setting long term goals for cities. Urbanism within the threshold of architecture and culture tends to glorify monumentality. This may be responsible for the emphasis on public spaces while analyzing urban architecture. The smaller structures that form the bulk of the cityscape which may also be typified in clusters are de-emphasized in morphological research in place of street design. Generally, urban design and architecture in recent times are more likely to be evaluated along the paradigm of sustainability [27].

The cityscape which is largely determined by the vision of previous and current architects and planners is never static, since the city will keep evolving. Futuristic building design that are supposed to alter the cityscape are only metaphors [28]. The public spaces within cities which give the city its characteristic appeal or identity belong to the state in most instances. The streets which serve as circulation within the city are evolving under the guidance of the planners and street designers. The landscaped areas of the city are collaborative efforts of architects and planners. Physical planning laws can give spatial limits for all these developments but may not necessarily affect the form. The individual efforts of the architects and designers, guided by the changing styles and movements will give rise to the chronology of forms that define the urban form. The urban morphology of any city should be decipherable from the buildings, the public spaces, the streets and the landscape if there has been no major deconstruction of the past within the city. Where the city originated from, to the present limits of the city are progressive curators of emerging styles in the development of the city. Clusters of buildings that developed around the same period will generally have a similar character [29]. This concept also transcends into neighborhoods that emerged at the same time. Urban morphological research and the tendency to reduce the findings into typologies have been discussed at length in previous studies $([30,31,27])$.

\section{The Urban Forms and Spaces of Lagos Island in 2019}

Despite the 20 years of physical planning laws and direct schemes on the island (table 1), the metropolitan form and space has not witnessed any radical changes in a preconceived direction. The major change that is easily noticeable is the level of congestion in the building clusters. The international style which is devoid of embellishments and decoration is repeated in a continuous building line along the streets especially in the gentrified areas. [32] describes this as a "typological process" in urban morphology. He explains the repetition of forms in a city as a cultural habit. The high continuous lines of buildings that line the streets on both sides give the "street canyon effect" [33] with a lot of noise pollution and air pollution that do not disperse easily. Urban heat islands are common in such conditions. The urban form is amorphous in these areas

Basically, the streets of the island are not wide enough to carry the activities that take place on them. Commercial activities spill unto road causing social problems like slow traffic and noise pollution. Petty crimes and poor sanitation also mar the outlook of the environment. The case of the city is that of a historic center. It has not been affected positively by gentrification which was mainly for economic reasons. The geometry of the building clusters is not very visible. It is completely engulfed by market activities. The city was polycentric at a stage in its evolution. It has now fused into a morass without a visible center.

There has always been controversy about the better urban form in terms of centricity. While [34] was able to defend a position that mono-centric urban formation is better, other urban planning theorists believe in decentralized core areas with a dispersion of commercial areas and poly-centric cities $([35,36])$. [25] believe that compact cities tend to be more efficient. Modern cities do not fit into the classical models of urban fabric where growth is evident from concentric rings around the center [37]. They are poly-centric and develop more along transportation lines between centers. Lagos Island started out as a mono-centric urban center. The frequent physical planning schemes have turned the whole city into a block form without any discernable center. Only the historic center where the traditional ruler resides shows attributes of centrality. The other centers which formed the nodes of development of the city have blended into the congestive continuum. Only the names of the pockets of the areas are suggestive of their earlier roles as centers of development. 
Table 1. Physical planning schemes on Lagos Island (1995-2015) and their effects on the metropolitan form and space.

\begin{tabular}{|c|c|c|}
\hline YEAR & PROGRAM DETAILS & EFFECTS ON THE URBAN FORM \\
\hline $1995-1998$ & $\begin{array}{l}\text { Urban Renewal Program by Lagos State Urban } \\
\text { Renewal Board. A state-led Gentrification program to } \\
\text { increase commercial land space via vertical } \\
\text { development. }\end{array}$ & $\begin{array}{l}\text { The major market streets changed from one storey clusters to } 4-5 \text { storey clusters. } \\
\text { The cityscapes were completely altered. Open spaces were taken over by } \\
\text { developers under this program which sought to generate income for original } \\
\text { property owners and Government. }\end{array}$ \\
\hline 1995 & $\begin{array}{l}\text { Reduction of permissible airspace between buildings } \\
\text { on Lagos Island. }\end{array}$ & $\begin{array}{l}\text { The city became more congested as buildings went to higher number of floors } \\
\text { without adequate air spaces and became fused within the clusters. }\end{array}$ \\
\hline 2000-2005 & $\begin{array}{l}\text { Reconstruction of major roads and sidewalks within } \\
\text { the island. }\end{array}$ & $\begin{array}{l}\text { The roads were better defined and the sidewalks formed a boundary for } \\
\text { commercial activities. }\end{array}$ \\
\hline $2007-2013$ & $\begin{array}{l}\text { Second phase of the road reconstruction and urban } \\
\text { renewal. This covered almost every main street on the } \\
\text { island. Sidewalks and drains were imposed on the } \\
\text { streets. Encroaching market stalls were demolished }\end{array}$ & $\begin{array}{l}\text { Street design standards could not be maintained and some roads were so narrow } \\
\text { that only one car can access them at a time. Commercial activities that were } \\
\text { delineated by the sidewalks in the former scheme were further compressed in the } \\
\text { new scheme. The trading eventually spilled back to the sidewalks and street } \\
\text { trading increased on the major roads. }\end{array}$ \\
\hline 2015 & $\begin{array}{l}\text { Relaxation of building approval requirements for } \\
\text { fresh applicants }\end{array}$ & No visible effects on the progression of form of the city. \\
\hline
\end{tabular}

The urban forms and cityscapes of Lagos Island are not uniform among the neighbourhoods. The core of the town, where the initial settlers first occupied is completely overrun by commercial activities. Retail stalls and shops line all the streets and the traditional compounds and living quarters are highly congested slum and squatter settlements. The major roads have office and institutional buildings that overlook the shops in the streets. The congestion on the street level is reflected in the skyline as the buildings appear very close to each other. The fringes of the island have some landscaped areas and more open access. These are results of recent upgrades and extension of the Island to its fringes and into the Lagoon for speculative reasons by the government. Property sizes on the island are very small due to commercial fragmentation and the land tenure system. While the regional average area of property size is $963.9 \mathrm{~m}^{2}, 92.8 \%$ of properties on the island have a land area of less than $500 \mathrm{~m}^{2}$ [38]. To correct such an infringement may require very obtrusive measures. The physical planning standards for Lagos Island are thus different from the regional standards when it comes to building setbacks.

The building count and building density have also increased throughout the Island. There has been a continuous decline in open spaces (Figure 1) and undeveloped land that had been put to other uses over the years. Car parks, building setbacks and undeveloped land parcels within partly developed properties are constantly being built up into commercial properties, thereby increasing the building density of the island (Table 2). The reality of congestion and inadequate infrastructure had been evident on the island since the 1990s [6]. The physical planning policies have not been able to address the issue. Rather the congestion is increasing as seen in the aerial imageries taken over time and evident in Table 2 .

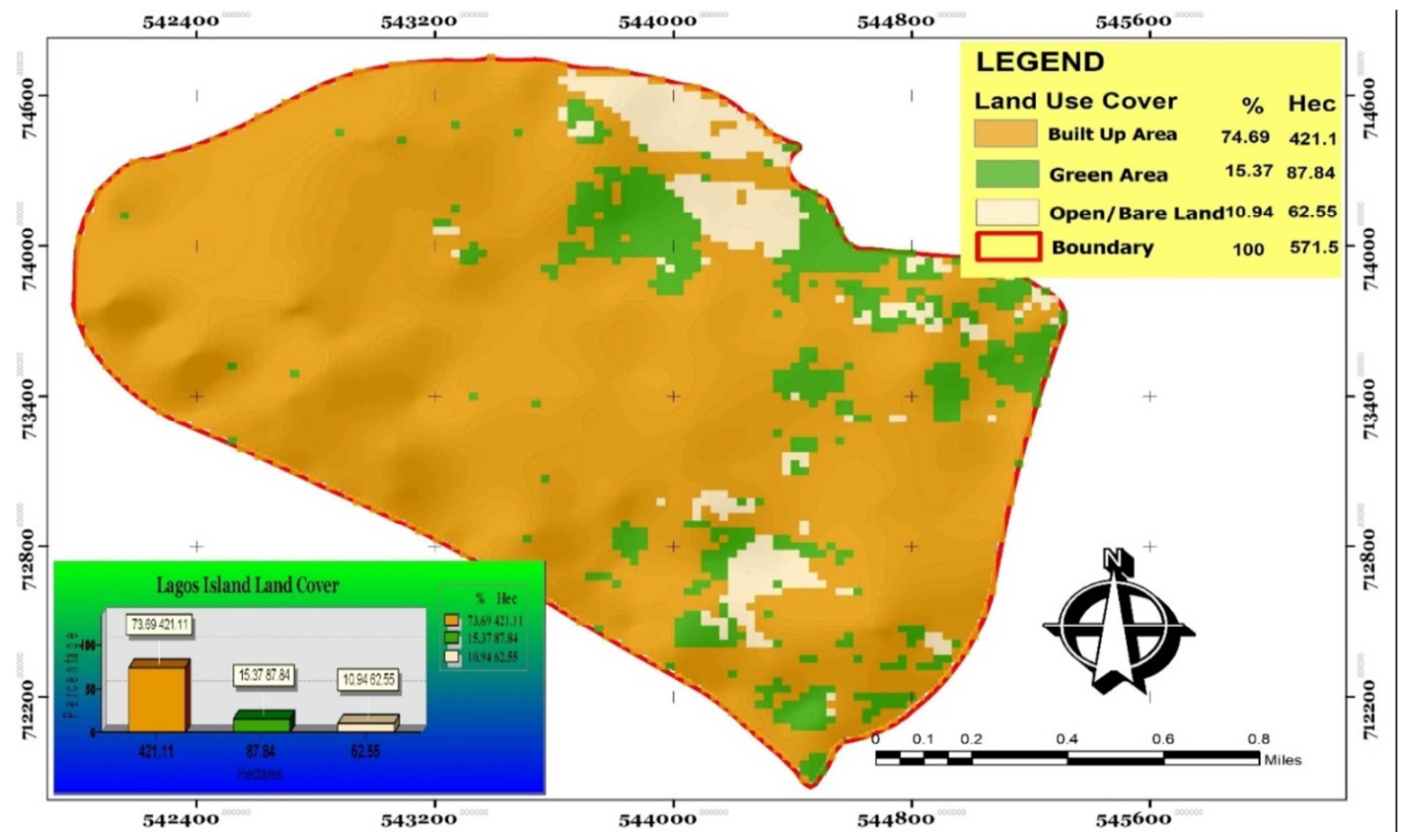

Figure 1. Lagos Island core area land use cover imagery (2019). 
Table 2. Building cover, count and density changes on lagos island (20002018).

\begin{tabular}{lll}
\hline Year & $\mathbf{2 0 0 0}$ & $\mathbf{2 0 1 8}$ \\
\hline Building Covered Land Area (Sq. Km) & 17.231 & 19.231 \\
Building Count & 555839 & 620381 \\
Building Density (Buildings per Sq. Meters) & 0.0289 & 0.0323 \\
Building Covered Land Area Chang Sq. Km) & 0 & 2.001 \\
Building Density Change (Buildings per Sq. Meters) & 0 & 0.003356 \\
Building Change & 0 & 64541 \\
\hline
\end{tabular}

The cityscapes

Distinct types of cityscapes are evident from the study. They are the results of the urban morphological processes determined by different rates and styles of commercialization of the indigenous Yoruba city forms and architecture. Prominent among them are the following; the congested high street; the high-rise central business district form; the slum and squatter urban sprawl; the market street.

The Congested High Street (CHS) which defines the areas directly behind the high-rise $\mathrm{CBD}$ and the eastern limits of the city are not as crowded as the interior of the city. The building clusters are still visible because of the wider streets and efforts to keep traffic moving. Government officials also try to limit street trading in these areas. The high style with closely clustered structures of four to six suspended floors line the streets. Physical planning encouraged vertical development in these areas in the 1970s. Offices for multinational companies and property investors' buildings abound in the area. The street level has been completely commercialized. The open spaces in the area which served as car parks were already built up during the period of the study (1995-2015). There are however multi-storey car parks and private parking lots within some premises. Majority of the car parking is done outside the area. The urban form in the area evolved from gentrification. Original Yoruba urban architecture was gradually eroded over the years as middle and high income individuals acquired properties from the family compounds to build commercial houses along the major streets. The peak of the gentrification process was the state led gentrification drive of the middle 1990s. The program gave more access to property developers in the area. The urban form attained a new threshold with the program. The urban morphology has been in the same direction till date.

The high-rise Central Business District (CBD) which covers the peripheral area to the south and west of the island has a very high concentration of high-rise buildings. It is occupied by offices. The architecture is typical for the modern cities around the world especially state capitals. Most of the buildings range between 16 and 30 floors high with regular geometrical shapes and modern finishes. It is still the high style architecture. Recent commercial infringements in the area have taken over the ground floors of the high-rise buildings. Street trading and commercial outlets have brought the market street to the once exclusive neighborhood. The urban form in this area did not evolve from the traditional Yoruba city forms and spaces. The area is contiguous to the quays where colonial ships berthed in the 19th century to trade with the indigenes. Colonial administration and quarters were located along the shores of the Lagos Lagoon in this area. Evidence of indigenous habitation is lacking in the original fringes of this eastern end of the island. People populated the northern fringes from where they had an easier access to the mainland. The CBD evolved from the colonial buildings and offices that dominated the area. Shipping companies, multinational trading companies and government offices dominated the landscape until the 1980s when business concerns like banks and oil companies moved into the areas and started putting up high-rise buildings to take advantage of the commercial centrality of the area. The compactness of the urban form that developed necessitated the sand-filling of the lagoon along the stretch to create more space for roads and car parking. Urban morphology in the area has been in the direction of other developing world office districts. The architecture continues to evolve into more contemporary forms and use of finishes. The only aberration is at the street level where the vista acquired from a farther distance, looking at the elevations suddenly changes. The street level is made up of branded shops, restaurants and service businesses as you have in wellorganized cities in the developing world is a different scenario on Lagos Island. Street trading, open stalls and peddlers of petty wares have completely taken over the street level. Only the Marina which faces the Lagoon is free from such encumbrances. The sidewalks abut the building lines along the Marina and petty trading is in the way of human traffic.

The slum and squatter sprawl stretch from street to street behind the congested high streets (CHS) and the markets streets. The central business district (CBD) is also not spared of the ensuing trend. The streets are lined with 4-5 storied buildings in front of the sprawl. A mix of indigenous population and traders have their living quarters in this congestion which is now city wide. The lack of enforcement of physical planning laws and relaxation of the development control limits have allowed the structures to fuse together without form. The rising cost of property in adjoining areas and the unwillingness of the state authorities to execute "eminent domain" has allowed the morass to continue in its spread and concentration. Slums may be regarded as a low cost housing solution to the urban setting [39]. They also provide accommodation in the vicinity of the industrial areas for a cheaper workforce. In the case of Lagos Island, the slum and squatter sprawl only provide accommodation for the traders who operate in the market city. There are no more factories on the island. All have relocated to the industrial complexes around the metropolis. The sprawl on Lagos Island does not only exacerbate the deplorable living conditions in the area but is enduring the environmental degradation therein. Congestion, poor sanitation and pollution by human waste are rife within the slums. The invasion of the traditional compounds by accommodation seekers during the urbanization and urban growth of the 
1960s and 1970s stimulated the development of the slum and squatter settlement. Till date, the land in the slums still belong to the traditional family lineages. The families also have many of their members living on the land with their tenants. Expansion of living spaces within the already congested property helps to increase income. Physical planning policies in the area shy away from directly impacting on the traditional compounds in any way that may be considered adverse. Public sentiments, fear of litigations and the influence of indigenes who are well represented in the municipal and state governments may be informing this present position. The areas are left to continue their organic development because physical planning policies are not vested on them. It is a case of "nonfeasance" rather than "malfeasance" of policy position.
The Market Streets (MS) are areas that were gentrified in the property rush of the 1980s and 1990s. All the inner streets of the Island have this type of landscape. The skyline is hardly visible with very narrow streets. Trading activities are very heavy at the street level in these areas. The vehicular traffic is grid locked with the trading activities during peak periods (Figure 2). Physical planning policies have executed urban renewal in these areas severally by constructing and reconstructing the roads and sidewalks. The building clusters are high style. The architecture is not easily discernable from the streets due to the constricted skyline. The indigenous forms of Yoruba architecture and Brazilian architecture have disappeared, leaving only poorly finished high style building clusters in their wake.

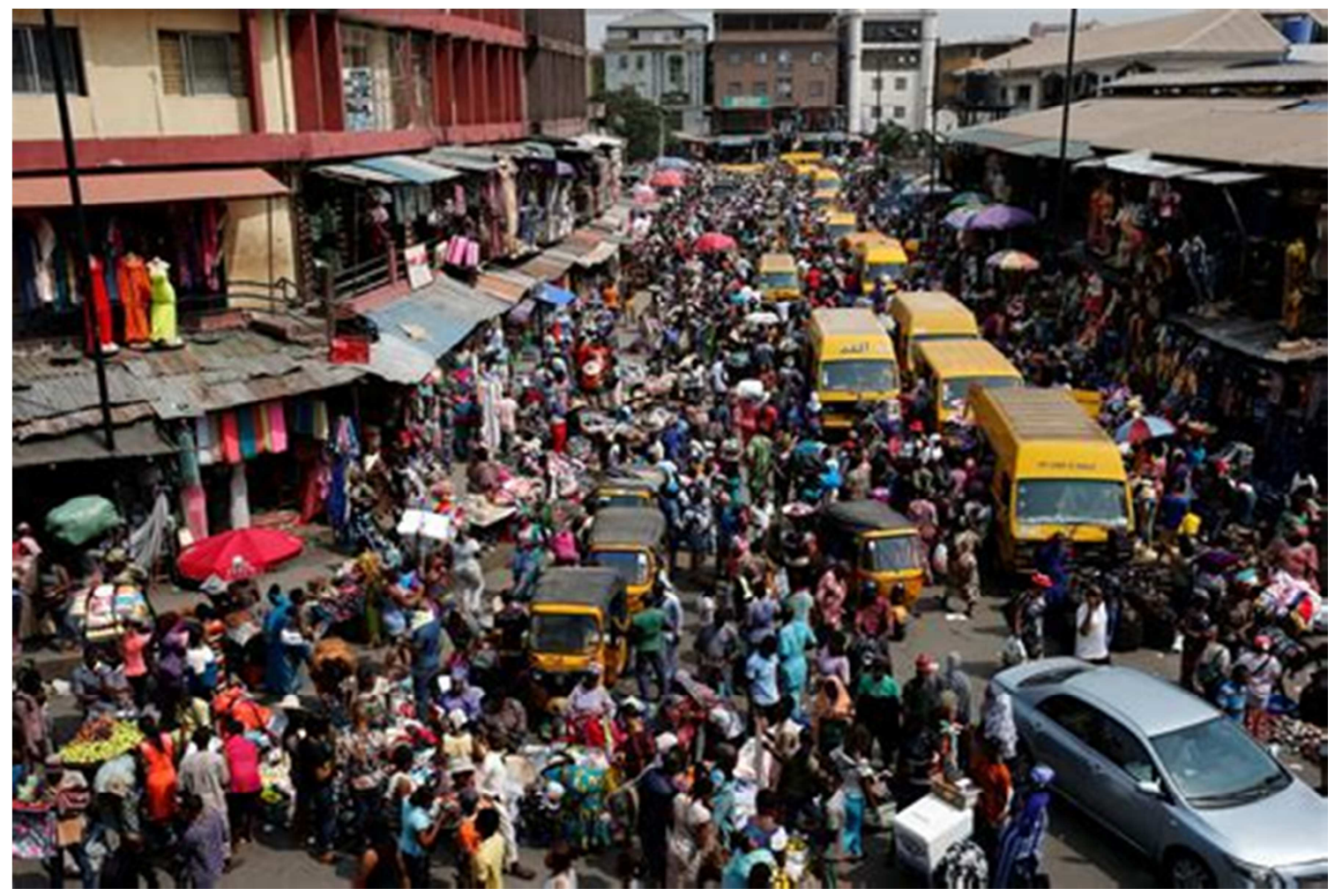

Figure 2. A typical market street on Lagos Island.

\section{Direct Concomitants of Physical Planning Policies on the Urban Morphology}

Over the years, physical planning policies and enforcement levels on Lagos Island have brought the urban setting to the following thresholds; spatial congestion, slum and squatter proliferation, failed land use planning, erosion of public open spaces and dysfunctional urban systems.

While architects' designs, socio-cultural evolution, town planning and state policies determine urban morphology, it must be realized that legislations are far more impacting on urban morphology via planning and control [40]. Physical planning in Lagos State has been going on for over one hundred years which makes it all the more culpable in the outcome of urban morphology in the area. Before the onset of official legislations in planning and development control, design of buildings and the culture of the people were stronger as determinants of the morphology. Physical planning policies are cognizant of the culture and impending building and city designs. They are also futuristic as they chart a path for the urban design to follow. They are executed through state legislations and town planning edicts. Physical planning on Lagos Island having been operational for over a century can thus be held responsible for the urban morphology through its direct acts and omissions.

The spatial congestion that pervades the island took many years to take its form. Rather than institute measures to control it, the physical planning policies tried to accommodate the existing situation by reducing the 
permissible setbacks for the area. There were also no strong enforcement and disciplinary measures to address contraventions of the setback limits. Temporary structures are not addressed in the physical planning laws. This is a very potent shortcoming in development control. Structures can be put up in the air spaces between buildings with impunity once they are not permanent structures. It has also allowed the development of highly fragmented properties that would have otherwise been unbuildable. Plots that have been subdivided into very small holdings that cannot qualify for statutory building approval are completely built up with materials that are not considered as permanent like wood and portable cabins because there is no legislation that prevents it. Once the property line which is not visually discernible is not violated, the owners erect multiple structures on the land. The markets that started out as neighborhood cultural commodity exchange centers have fused into a continuous sprawl. There are no visible boundaries and each market extends to the next market along the major roads. Daytime activities on the island tend towards a citywide bazaar. Physical planning has not been able to bring an order into the congestion that characterizes the city.

The slums that form the back streets and the street elevation of some major streets are typical examples of socio-spatial dysfunctionalism that have become heavily engrained in the urban setting. The few attempts at gentrification have only aggravated the condition. The people living in the area work and trade there. The contiguous settlements like Ikoyi, Victoria Island and Ebute-Meta are either too expensive or also congested. Only a very obtrusive and far reaching solution can remove the slum. Forced eviction that the state government deployed to solve the slum problems in Maroko [41] and some parts of Ijora-Badiya [42] may be very difficult to apply on Lagos Island. The population is very large and most of the properties have legal titles. It will be difficult to execute eminent domain due to the social problems the large population will exert on the contiguous areas. If the physical planning policies had been designed to curtail the spread of the slums and squatter settlements, the present situation would not have been so intransigent. Slums are products of unregulated organic urban development. Only planning and development control can curtail them. Although slums can be very efficient in infrastructural consumption [43] and provide cheap mass housing at the center of the urban spread [39], they remain a blight in the urban setting.

The land use patterns in well-organized cities are constantly pre-empted and planned, for balanced development. Once land use patterns are planned, efforts must be made to enforce the provisions of the design. The Lagos Island town planning office and the Lagos State Ministry of Physical Planning have laid out land use plans and allocations for the area. The allocations are consulted before the issuance of approval for new building designs. There are however no visible restrictions on the conversion of land use, leading to large scale abuse. The eruption of temporary structures, mostly used for trading also affects the land use planning for the area. The allocation of commercial land use to properties and areas in Lagos State does not distinguish among the different types of commercial uses. Commercial land use in Lagos State can be used to represent retail shops, wholesale facilities, offices, warehouses, hotels and any other use of the land that generates income. Such a generalization makes the organization of the urban outlook very challenging. Generally, the properties abutting the major roads are allocated to commercial uses. It is expected that their proximity to the roads, makes them more attractive for commercial uses which in turn generate more taxes for the government. Land use planning is a viable tool for organizing the urban space for efficiency in its daily operations [44]. If land use planning is absent or not adhered to, a chaotic situation may occur in the urban space.

Another concomitant of failure in land use planning is the loss of public open spaces. Public open spaces have social and cultural values and can also interface in broader acts of ecological balance [45]. The open spaces on the island evolved through a socio-cultural process that spanned over a century. Where urban morphology progresses in a direction that completely obliterates public open spaces, certain values would have been lost in the society. Physical planning on the island not only failed to protect the public open spaces, it was actively involved in the allocation of such spaces to developers for pecuniary benefits.

Urban systems, especially in the realms of urban infrastructure and municipal services are largely dependent on well-organized urban settings to function properly. Physical planning should be used to support urban systems by organizing the built up structures and infrastructures for better efficiency. On Lagos Island, the rowdiness, congestion and lack of spatial control have made the provision of infrastructure like good drains, potable water and electricity lines very difficult to install and maintain. Municipal services like refuse disposal and urban transportation are clogged and dysfunctional. Flooding is becoming more pronounced on the island as the years go by. The increasing pressure on the drains and the failure of other urban services like refuse disposal coupled with the high precipitation gives rise to incidents of flooding during the very wet months. The island is flat and is not easily drained.

Efforts to improve these infrastructure and services greatly deplete the resources of the authorities without corresponding effects on the environment. Ad hoc measures like strong penalties are sometimes taken to resolve serious issues. The underlying problems of spatial organization and order may need to be resolved to improve the urban systems delivery.

\section{Conclusion}

The architecture of an area cannot be separated from the culture of the area [46]. The urban morphology of a city at any point time is one of the indicators of the evolving culture of the area. Culture itself, is the life of the city. As it manifests, it becomes fused into the form of the city. It cannot be easily isolated into elements that can be assembled 
and deconstructed. This is why the domain of urban morphology is very cumbersome to demonstrate. A correlated approach with notions in culture, tradition, history, state policies, heritage and new theories in urbanism is needed to explain urban morphology [47, 48]. Urban morphology can also be explained as scenic manifestations of the history of a city [49]. The urban architecture of Lagos Island, evolved from the sedentary traditional forms through the Brazilian style to the high style within the 1900s. During the period of this study, the architecture had become a fusion of all the styles bound together by the formless urban sprawl. The city is a melting pot of various peoples from all over West Africa who came along with their different cultures. Such a fusion is gradually producing a unique culture that can only flourish in the slums of Western Nigeria. The physical planning policies on Lagos Island were econocentric by nature and never intended to protect the culture and heritage of the indigenous population. The evolved cityscapes are default forms that are comparable with similar situations in Southeast Asia and Central America. A lot of social problems are associated with the urban forms that make up this type of cities. The direction of the urban morphology is undesirable. Future physical planning measures should consider reinventing the city along new lines of functionalism and more efficient urban systems.

\section{References}

[1] Asomani-Boateng, Raymond. (2011) "Borrowing from the past to sustain the present and the future: indigenous African urban forms, architecture, and sustainable urban development in contemporary Africa." Journal of Urbanism: International Research on Placemaking and Urban Sustainability 4.3 (2011): 239-262.

[2] Saleh, Mohammed Abdullah Eben. (2001). "The evolution of planning \& urban theory from the perspective of vernacular design: MOMRA initiatives in improving Saudi Arabian neighbourhoods." Land Use Policy 18.2 (2001): 179-190.

[3] Garba, Shaibu Bala. (2004) "Managing urban growth and development in the Riyadh metropolitan area, Saudi Arabia." Habitat International 28.4 (2004): 593-608.

[4] Aluko, Ola. (2011) "Development Control in Lagos State: an assessment of public compliance to space standards for urban development." African research review 5.5 (2011): 169-184.

[5] Bradley, Steven W., Jeffery S. McMullen, Kendall Artz, and Edward M. Simiyu. (2012) "Capital is not enough: Innovation in developing economies." Journal of Management Studies 49, no. 4 (2012): 684-717.

[6] Gandy, Matthew. (2006). "Planning, anti-planning, and the infrastructure crisis facing metropolitan Lagos." Cities in contemporary Africa. Palgrave Macmillan, New York, 2006. 247-264.

[7] Ilesanmi, Adetokunbo Oluwole. (2010). "Urban sustainability in the context of Lagos mega-city." Journal of Geography and Regional Planning 3.10 (2010): 240-252.

[8] Dekker, Karien, and Ronald Van Kempen. (2004) "Urban governance within the Big Cities Policy: ideals and practice in Den Haag, the Netherlands." Cities 21.2 (2004): 109-117.

[9] Bengston, David N., Jennifer O. Fletcher, and Kristen C. Nelson. (2004). "Public policies for managing urban growth and protecting open space: policy instruments and lessons learned in the United States." Landscape and urban planning 69.2-3 (2004): 271-286.

[10] Grant, J. L. (2009). Theory and practice in planning the suburbs: Challenges to implementing new urbanism, smart growth, and sustainability principles. Planning Theory \& Practice, 10 (1), 11-33.

[11] Brenner N, Marcuse P and Mayer M. (2012). Cities for people, not for profit: critical urban theory and the right of the city. Routledge, 2012.

[12] Clark, Roger H., and Michael Pause. (2012). Precedents in architecture: analytic diagrams, formative ideas, and partis. John Wiley \& Sons, 2012.

[13] Aduwo, Adeboye. (1999). Historical preview of town planning in Lagos. Urban and Regional Planning in Nigeria: A Collection of Readings. NITP Lagos Chapter, Lagos. (1999).

[14] Seun, Adetiba Adedamola. (2015). "Malaria and Sanitation in Colonial Lagos: A Historical Appraisal." History Research 3.6 (2015): 65 .

[15] Nightingale, C. H. (2012). Segregation: A global history of divided cities. University of Chicago Press.

[16] Olomola, A. O. (1999). Pre 1929 History of Town Planning in Lagos. Urban and Regional Planning in Nigeria: A book of Reading.

[17] Ezema, Isidore C., Pearl Akunnaya Opoko, and Adedapo Adewunmi Oluwatayo. (2016) "Urban regeneration through state-led, new-build gentrification in Lagos inner city, Nigeria." International Journal of Applied Environmental Sciences 11.1 (2016): 135-146.

[18] Farr, Douglas. (2011) Sustainable urbanism: Urban design with nature. John Wiley \& Sons, 2011.

[19] Sharifi, Ayyoob. (2006). "From Garden City to Eco-urbanism: The quest for sustainable neighborhood development." Sustainable Cities and Society 20 (2016): 1-16.

[20] Fu, Yang, and Xiaoling Zhang. (2017) "Trajectory of urban sustainability concepts: A 35-year bibliometric analysis." Cities 60 (2017): 113-123.

[21] Arkin, Lois, and Richard W. Crenshaw. (1992) Sustainable cities: concepts and strategies for eco-city development. EcoHome Media, 1992.

[22] Leydesdorff, Loet, and Mark Deakin. (2011). "The triple helix model of smart cities: a neo-evolutionary perspective." Smart Cities. Routledge, 2013. 146-161.

[23] Reed, Tracie J., Peggi L. Clouston, Simi Hoque, and Paul R. Fisette. (2010). "An analysis of LEED and BREEAM assessment methods for educational institutions." Journal of Green Building 5, no. 1 (2010): 132-154.

[24] Schweber, Libby, and Hasan Haroglu. (2014). "Comparing the fit between BREEAM assessment and design processes." Building Research \& Information 42.3 (2014): 300-317. 
[25] Yeh, Anthony Gar-On, and Xia Li. (2001). "A constrained CA model for the simulation and planning of sustainable urban forms by using GIS." Environment and Planning B: Planning and Design 28.5 (2001): 733-753.

[26] H. Wang, Q. He, X. Liu, Y. Zhuang, S. Hong. (2012). Global urbanization research from 1991 to 2009: A systematic research review. Landscape and Urban Planning, 104 (3) (2012), pp. 299-309

[27] Altomonte, S., Rutherford, P., \& Wilson, R. (2014). Mapping the way forward: Education for sustainability in architecture and urban design. Corporate Social Responsibility and Environmental Management, 21 (3), 143-154.

[28] Heinonen, Sirkka, and Matti Minkkinen. (2016). "Interpreting built cityscape: Deconstructing the metaphorical messages of futuristic buildings." Futures 84 (2016): 163-177.

[29] Uzun, C. Nil (2003). "The impact of urban renewal and gentrification on urban fabric: three cases in Turkey." Tijdschrift voor economische en sociale geografie 94.3 (2003): 363-375.

[30] Whitehand, Jeremy WR. (2007). "Conzenian urban morphology and urban landscapes." 6th International Space Syntax Symposium. 2007.

[31] Hall, Tony. (2008). "The form-based development plan: bridging the gap between theory and practice in urban morphology." Urban Morphology 12.2 (2008): 77-95.

[32] Kropf, Karl S. (2001) "Conceptions of change in the built environment." Urban Morphology 5.1 (2001): 29-46.

[33] Tang, U. W., and Z. S. Wang. (2007). "Influences of urban forms on traffic-induced noise and air pollution: Results from a modelling system." Environmental Modelling \& Software 22.12 (2007): 1750-1764.

[34] Banzhaf, H. S., \& Lavery, N. (2010). Can the land tax help curb urban sprawl? Evidence from growth patterns in Pennsylvania. Journal of Urban Economics, 67 (2), 169-179.

[35] Sun, H., Forsythe, W., \& Waters, N. (2007). Modeling urban land use change and urban sprawl: Calgary, Alberta, Canada. Networks and spatial economics, 7 (4), 353-376.

[36] Gaigné, C., Riou, S., \& Thisse, J. F. (2012). Are compact cities environmentally friendly?. Journal of Urban Economics, $72(2-3), 123-136$.
[37] Berghauser Pont, M., \& Haupt, P. (2007). The Spacemate: Density and the typomorphology of the urban fabric. Urbanism laboratory for cities and regions: progress of research issues in urbanism.

[38] Aluko, Ola. (2011) "The effects of location and neighbourhood attributes on housing values in metropolitan Lagos." Ethiopian Journal of Environmental Studies and Management 4.2 (2011): 69-82.

[39] Jain, Manisha, Jörg Knieling, and Hannes Taubenböck. (2006). "Urban transformation in the National Capital Territory of Delhi, India: The emergence and growth of slums?" Habitat international 48 (2015): 87-96.

[40] Gauthiez, Bernard. (2004). "The history of urban morphology." Urban morphology 8 (2004): 71-90.

[41] Daniel, Mallo Maren, Wapwera, S. D., Akande, E. M., Musa, C. C. and Aliyu, A. A. (2015) "Slum housing conditions and eradication practices in some selected Nigerian cities." (2015).

[42] Morka, Felix C. (2007). "A place to live: A case study of the Ijora-Badia community in Lagos, Nigeria." Unpublished case study prepared for Global Report on Human Settlements (2007).

[43] Castells-Quintana, David. (2017) "Malthus living in a slum: Urban concentration, infrastructure and economic growth." Journal of Urban Economics 98 (2017): 158-173.

[44] Munroe, Darla K., Cynthia Croissant, and Abigail M. York. (2005). "Land use policy and landscape fragmentation in an urbanizing region: Assessing the impact of zoning." Applied Geography 25. 2 (2005): 121-141.

[45] Thompson, Catharine Ward. (2002). "Urban open space in the 21 st century." Landscape and urban planning 60. 2 (2002): 5972 .

[46] Mihaila, M. (2014). City architecture as cultural ingredient. Procedia-Social and Behavioral Sciences, 149, 565-569.

[47] Jencks, Charles, and Karl Kropf. (2006). Theories and manifestoes of contemporary architecture. Vol. 312. Chichester: Academy Editions, 1997.

[48] Frankelius, 2009 Frankelius, Per. (2009). "Questioning two myths in innovation literature." The Journal of High Technology Management Research 20.1 (2009): 40-51.

[49] McCarter, Robert, and Juhani Pallasmaa. (2012). Understanding architecture. Phaidon, 2012. 